\title{
Effect of Electron Beam Irradiation on Forensic Evidence. 2. Analysis of Writing Inks on Porous Surfaces
}

\begin{abstract}
The effect of electron beam irradiation on a series of different writing inks is described. As the anthrax-tainted letters were discovered in October 2001, the U.S. government began to experiment with the use of the electron beam irradiation process for destroying such biological agents. Plans initially considered a large-scale countrywide use of this technology. However, over time the scope of this plan as well as the radiation dosage were reduced, especially when some adverse consequences to mailed items subjected to this process were observed. Little data existed at the time to characterize what level of damage might be expected to occur with common items sent through the mail. This was especially important to museums and other institutions that routinely ship valuable and historic items through the mail. Although the Smithsonian Institution initiated some studies of the effect of electron beam irradiation on archived materials, little data existed on the effect that this process would have on forensic evidence. Approximately 97 different black, blue, red, green, and yellow writing inks were selected. Writing ink types included ballpoint, gel, plastic/felt tip, and rollerball. All noncontrol samples were subjected to standard mail irradiation conditions used by the U.S. Postal Service at the time this experiment was performed. A video spectral comparator and thin-layer chromatography (TLC) analysis were used to evaluate both the control and the irradiated samples. Some published studies reported changes in the presence/absence of dye bands in the chromatograms of irradiated writing inks. Some of these studies report the formation of additional dye bands on the chromatogram while others report missing dye bands. However, using standard testing guidelines and procedures, none of the 97 irradiated inks tested were found to show any significant optical or chemical differences from the control samples. In addition, random testing of some of the ink samples using a second solvent system did not reveal any changes. However, one control ink did show some minor changes in optical properties and dye characteristics over time (but not TLC) while the irradiated sample remained stable. Significant changes in the ultraviolet fluorescence characteristics of the irradiated paper samples themselves (not inks) were also observed.
\end{abstract}

KEYWORDS: forensic science, writing inks, inks, ink analysis, thin-layer chromatography, mail irradiation, electron beam irradiation

The routine irradiation of mail is a relatively recent development and has a limited scope; therefore, little data exist on the effects of such treatments on forensic evidence. In a previous paper, the authors investigated the effects of such conditions on the ability to visualize latent prints on porous and nonporous surfaces (1). Significant degradation of latent print residue was found to occur on both surface types. As the U.S. Secret Service routinely performs chemical analyses of writing ink samples on questioned documents, a decision was made to investigate what effects the irradiation process would have on such examinations.

Several relatively recent studies have investigated the impact of irradiation treatments on archival materials (2) and writing inks $(3,4)$. These studies were conducted primarily by the Smithsonian Center for Materials Research and Education (Suitland, MD). In one study, seven of 26 inks tested showed changes in the TLC chromatograms (3). The inks affected were red and blue ballpoint. With six of the seven inks, a new dye band was detected after chromatographic analysis. With the seventh ink, the relative mobilities (i.e., retardation factors) of the dye components were altered. Radiation dosages in this study were estimated to be up to five times the dosage encountered in the routine mail irradiation

${ }^{1}$ U.S. Secret Service, Forensic Services Division, Research Section, $950 \mathrm{H}$ Street, NW, Washington, DC 20223.

${ }^{2}$ Student Intern, University of Michigan, Ann Arbor, MI 48109.

All references pertaining to specific manufacturers or their products are for information purposes only and do not imply endorsement by the authors or the United States Secret Service.

Received 5 Sept. 2005; and in revised form 7 Oct. 2006; accepted 29 Oct. 2006; published 5 April 2007. process. The second study found additional ink changes, including altered mobilities and new dye components even at the lower radiation dosages associated with mail irradiation (4). It should be noted that these studies used different extraction solvents (acetone and ethyl acetate) and solvent systems for eluting TLC plates. The authors examined 97 different writing inks of various colors (132 samples total, including 35 aged samples) before and after irradiation and compared their thin-layer chromatograms.

The U.S. Secret Service maintains an International Ink Library that contains samples of more than 9000 inks from around the world, some dating back to the 1920s (5). Although the library contains primarily writing ink samples, it also contains printing, marking, typewriter ribbon, and stamp pad inks. The origin of this ink library dates back to the early 1960s, when Werner Hofmann of the Zurich Cantonal Police in Switzerland established a modest collection of black and blue European ballpoint inks (L. Olson, personal communication, 2005). This collection was eventually incorporated into what would become the International Ink Library. Additional ink samples were contributed by the Federal Bureau of Investigation, United States Postal Service, and several private document examiners. In 1968, Richard Brunelle, a chemist with the Internal Revenue Service's (IRS) Alcohol and Tobacco Tax Division Laboratory (which later separated from the IRS and became the Bureau of Alcohol, Tobbaco, and Firearms [BATF]), began to contact domestic ink producers and significantly expanded the library's contents. In the first year of the effort, more than 2000 samples were collected.

In an effort to relieve the BATF ink analysis case load (which was largely due to submissions from the IRS), the IRS laboratory and BATF began to share the resources of the ink library in June 
of 1987. This mutual agreement also involved a decision by the BATF to train an ink chemist for the IRS laboratory as well. Initially, the IRS was interested in only black, blue, red, and green ballpoint ink samples from the BATF ink library. Subsequently, the IRS collected over 1500 open market (i.e., commercial offthe-shelf) ink samples and contributed them to the BATF library. To date, the IRS laboratory has contributed a total of approximately 2300 open market samples to the library. In 1988, the ink library was ultimately transferred from the BATF to the U.S. Secret Service. These two libraries are now constantly being updated with samples submitted from the major ink manufacturers (primarily within the United States, Europe, and Japan) as well as with open-market purchases from domestic and foreign sources.

\section{Materials and Methods}

A total of 97 different inks were tested and evaluated during this study, of which 27 were black, 33 blue, 18 red, 12 green, and seven yellow specimens. Appendices A-E contain lists of all of the inks that were chosen for this study. A series of sample sheets were prepared by scribbling each ink within two similar rectangular boxes. The boxes were numbered and then separated, one to act as a control and the other to be irradiated. Thirty-five additional ink samples were included as well. These samples were duplicates of some of the original 97 that had been deposited on paper (typically Whatman filter paper) at various times within the past 26 years. These samples were included to determine whether there would be any differences with samples that had been allowed to dry on paper for a number of years. Two types of paper were used: Xerox Premium Multipurpose 4024 Paper $\left(8.5^{\prime \prime} \times 11^{\prime \prime}, 20 \mathrm{lb}, 88\right.$ brightness $)$ and white, blue-lined notepad paper $\left(8.5^{\prime \prime} \times 11^{\prime \prime}, 16 \mathrm{lb}, 50 \%\right.$ recycled content, purchased from GSA (Washington, DC), NSN 7530-01-124-5660).

The electron beam irradiation process was performed at a facility in New Jersey. The exact radiation dosage and conditions will not be specified for operational security reasons. As a point of comparison, typical irradiation dosages for foods can vary from $1 \mathrm{kGy}$ for fruit, $3 \mathrm{kGy}$ for poultry, and up to $30 \mathrm{kGy}$ for spices and seasonings (6). The unit of measurement for absorbed radiation dosages is the Gray, which is abbreviated Gy, and is equivalent to 100 rads (7). The U.S. Environmental Protection Agency estimates that mail irradiation dosages are equivalent to approximately two million times that of a chest X-ray, which they claim is more than sufficient to kill any biological agent (8). It is important to note that it is nearly impossible to expose all of the samples to a specified dosage of radiation; rather, the U.S. Postal Service guarantees that all specimens will receive a minimum radiation dosage.

The Foster \& Freeman Video Spectral Comparator 2000 high resolution (VSC [Evesham, Worcestershire, UK] $2000 \mathrm{HR}$ ) was used to evaluate the optical properties of both the control and irradiated ink and paper samples. Any differences in infrared reflectance (IRR), infrared luminescence (IRL), and ultraviolet fluorescence were noted. In addition, absorptance spectra of all ink samples were recorded. It should be noted that the VSC 2000 HR refers to these graphs as "absorption" rather than "absorptance." These two terms are essentially interchangeable, but should not be confused with the related term absorbance. To gain a better understanding of this concept, it should be noted that the radiant flux incident upon a surface or medium undergoes three processes: transmission, reflection, and absorption (9). The application of the conservation of energy leads to the statement that transmission $(\tau)$, reflection $(\rho)$, and absorption $(\alpha)$ of the incident flux are equal to unity, or $\tau+\rho+\alpha=1$. When dealing with opaque items, $\tau$ is generally assumed to be 0 ; thus, absorption (or absorptance) is defined by $1-\rho$. Thus, absorptance is the fraction of radiant flux that is absorbed $\left(\alpha=\Phi_{\mathrm{a}} / \Phi_{\mathrm{i}}\right.$, where $\Phi_{\mathrm{a}}$ is the radiant flux absorbed and $\Phi_{\mathrm{i}}$ is the incident radiant flux) and is expressed as a fraction or percentage.

The TLC analyses were performed in accordance with ASTM guideline E1422-01 (10), except where noted below. Silica gel glass plates (Merck Kieselgel 60, EM Science \#5721-7) were used for all TLC analyses. Approximately five to eight microplugs ( $1 \mathrm{~mm}$ diameter) of ink were removed from each ink sample. All ballpoint inks were extracted with pyridine and all nonballpoint inks were extracted using a 50:50 mixture of ethanol and distilled water. After spotting, the plates were placed in a $100^{\circ} \mathrm{C}$ oven for $c$. $10 \mathrm{~min}$ to drive off any residual extraction solvent(s). It should be noted that ASTM guideline E1422-01 recommends that the plates be air-dried. However, internal research has found that heating plates at $100^{\circ} \mathrm{C}$ for short periods of time does not induce changes in the ink's colorants. All plates were developed using solvent system 1, which is a 70:35:30 mixture of ethyl acetate, ethanol, and distilled water, respectively. The solvent front was allowed to elute a distance of $4 \mathrm{~cm}$ from the origin of the ink spots.

A secondary set of TLC analyses were performed on random samples from each ink color set using solvent system 2. This solvent system, described in the aforementioned ASTM guideline, is a 50:10:15 mixture of $n$-butanol, ethanol, and water. This solvent system was used in the previous Smithsonian studies as well $(3,4)$. The authors decided to see whether some of the observations noted in these studies could be reproduced using this solvent system. With the exception of the solvent system, all other procedures for analyzing the inks were the same as described in the preceding paragraph.

\section{Results}

\section{Optical Properties}

Overall, the optical properties (e.g., IRR, IRL) of all of the ink samples did not appear to change after the irradiation process. Although there were some minor intensity differences noted in the absorptance spectra (most likely due to minor differences in ink concentrations of the control and irradiated samples), the shapes of the curves for those inks were not significantly altered after irradiation.

There was one minor exception to this trend. Although one particular blue ink (ink 55) initially did not show any differences between the control and irradiated samples, the color of these two ink samples on blue-lined notepad paper changed noticeably over time. Interestingly, it was the color of the irradiated sample (55A) on lined paper that remained stable while the control sample (55B) became more gray/black in color over a 12 -month period. The color difference can be observed in Fig. 1. This color change did not occur with the same ink on unlined photocopy paper (Fig. 2). One possible explanation for this may involve a slight difference in $\mathrm{pH}$ noted between the lined and unlined papers. A crude estimate of the $\mathrm{pH}$ (using a pHydrion Insta-chek Surface $\mathrm{pH}$ Pencil, Micro Essential Laboratory, Inc., Brooklyn, NY) indicated that the lined paper was $c .1 \mathrm{pH}$ unit below that of the unlined photocopy paper ( $\mathrm{pH}$ range $6-7$ vs. $7-8$, respectively). The ink industry has at times added acids (e.g., oleic acid) to some ink formulations to stabilize certain basic dyes (Dr Ben Fabian, National Ink Inc., Santee, CA, personal communication, May 2006). It is possible that the decrease in $\mathrm{pH}$ observed in the lined 

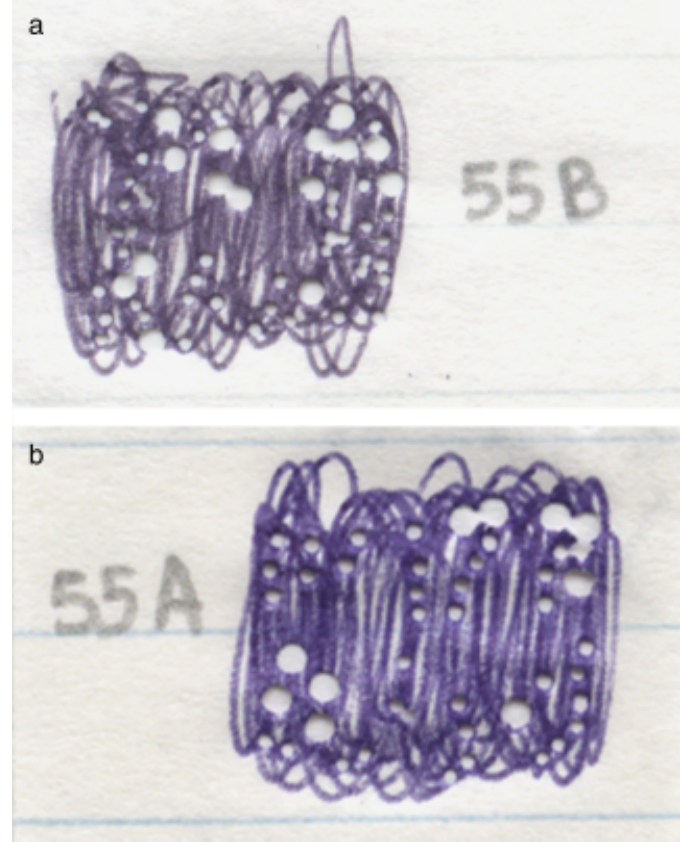

FIG. 1-(a) An image of the irradiated ink (55A) on blue-lined notepad paper. (b) An image of the control ink (55B) on blue-lined notepad paper. Although the images appear to be identical as reproduced in black and white, the differences can be discerned in the online color version of this article.

paper sample may have stabilized the particular basic dyes contained in this ink formulation while the unlined paper did not.

Upon further study, it was noted that the color change on lined paper was reflected in the absorptance spectrum as well as in the TLC analysis. An absorptance spectrum taken just after the irradiation process can be seen in Fig. $3 a$, while a more recent one can be seen in Fig. $3 b$. Note how the absorptance curve tends to flatten out in the visible region, which in effect makes it begin
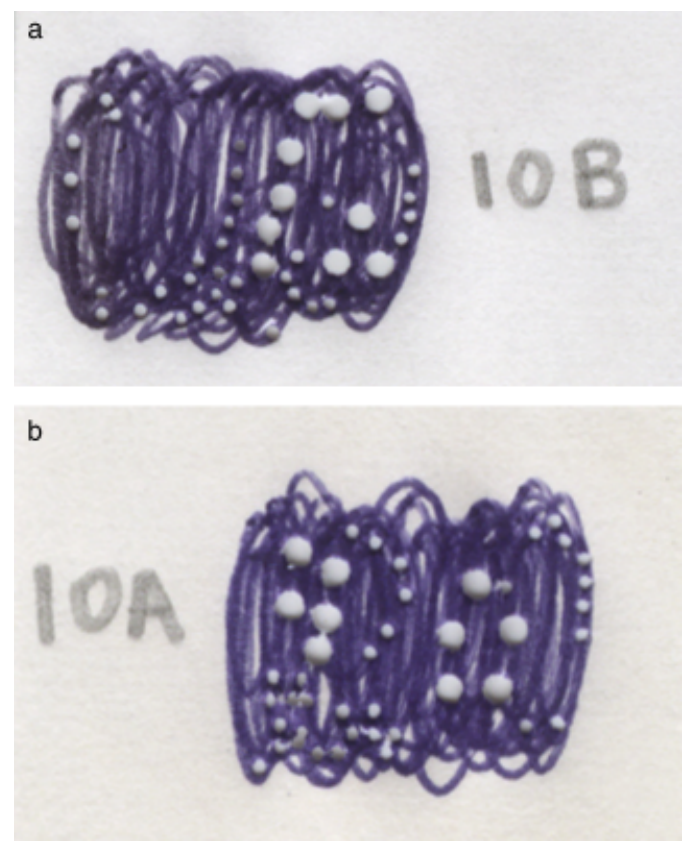

FIG. 2-(a) An image of the irradiated in (10A) on photocopy paper. Sample 10B is the same ink formulation as sample 55A. (b) An image of the control ink (10A) on photocopy paper. Sample 10A is the same ink formulation as sample $55 \mathrm{~A}$.
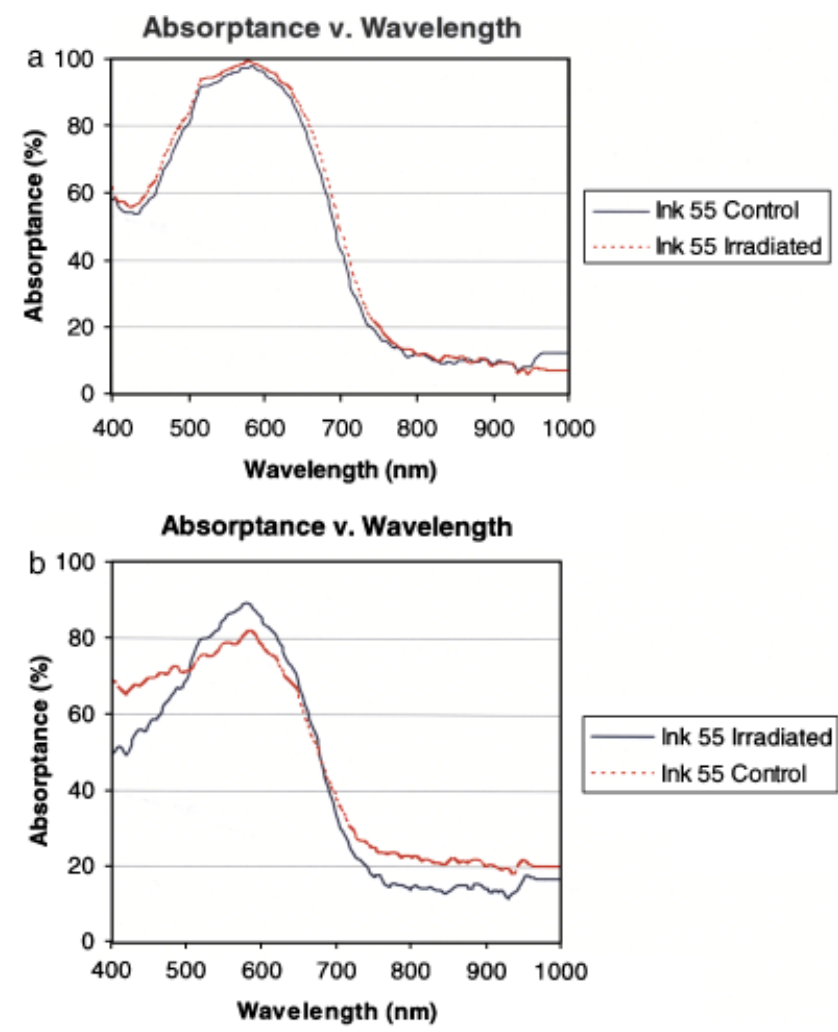

FIG. 3-(a) A graph of absoptance versus wavelength for ink 55 before and after irradiation. These data were obtained soon after the ink sample was exposed to the irradiation process. (b) A graph of absorptance versus wavelength for ink 55 before and after irradiation. These data were obtained c. 1 year after the ink sample was exposed to the irradiation process. Although the images appear to be identical as reproduced in black and white, the difference can be discerned in the online version of this article.

to resemble the spectral characteristics of a black ink rather than a blue one. An image of the TLC plate run c. 9 months after irradiation can be seen in Fig. 4. The two dark blue bands are clearly not present in the control (refer to the upper cluster of bands $c .3 \mathrm{~cm}$ from the origin in lane 5 in Fig. 4), but they are present in the irradiated sample. The TLC analysis of this sample was repeated twice and each time the dark blue bands were not

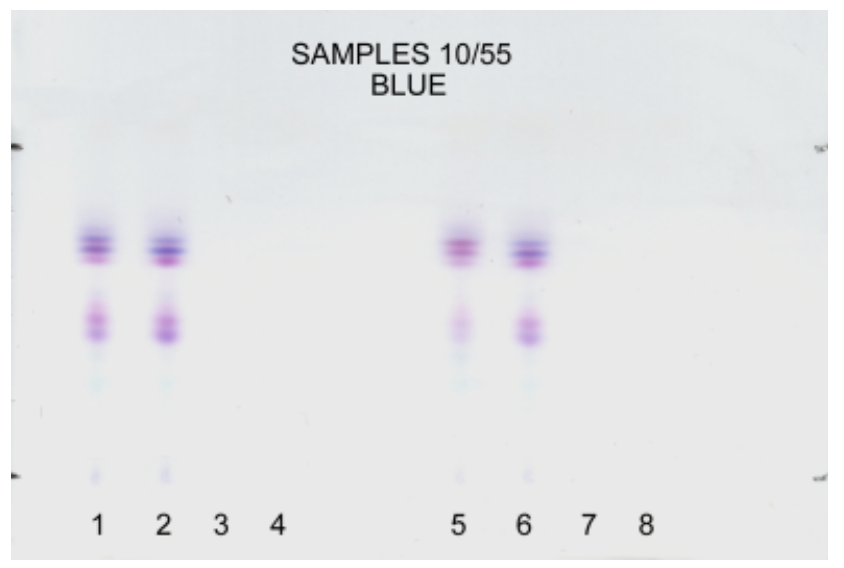

FIG. 4-An image of a thin layer chromatography (TLC) plate for ink samples 10 and 55. The two ink samples have the same formulation; however, ink 10 was deposited on photocopy paper, whereas ink 55 was deposited on blue-lined notepad paper. This TLC plate was developed c. 9 months after the samples were exposed to the irradiation process. 


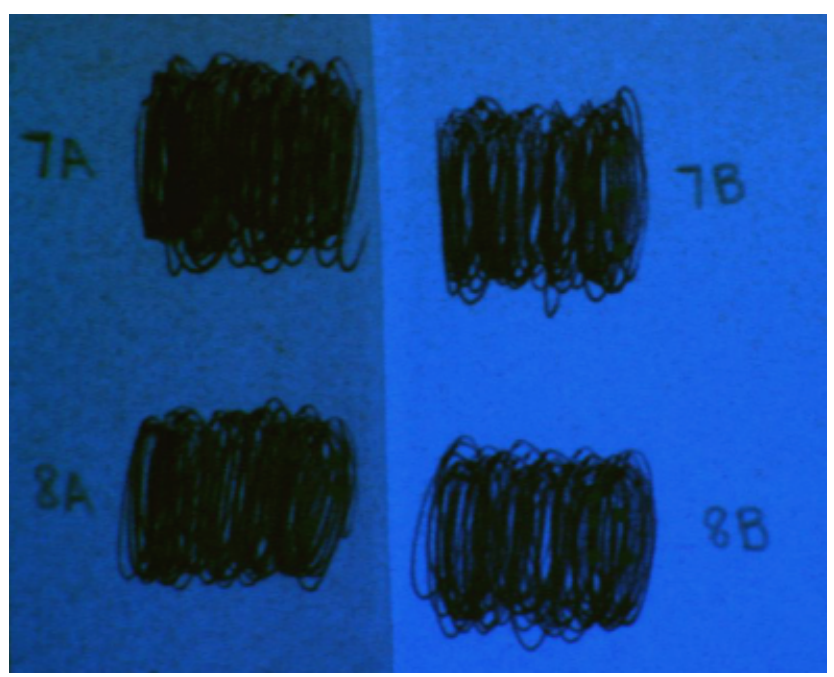

FIG. 5-An image of two inks deposited on photocopy paper. The paper on the left contains the irradiated samples for those two inks. The paper on the right contains the control samples for those two inks. Note the decreased intensity of the ultraviolet fluorescence of the paper on the left (irradiated) compared with the paper on the right (control).

present in the control sample. It should be noted that for the TLC plates in this and subsequent figures, a total of four spots for each ink were deposited. When viewing a standard two-ink sample plate from left to right, the spot sequence would be as follows: unlined paper ink control (lane 1); unlined paper ink irradiated (lane 2); unlined paper control blank (lane 3); unlined paper irradiated blank (lane 4); lined paper ink control (lane 5); lined paper ink irradiated (lane 6); lined paper control blank (lane 6); and lined paper irradiated blank (lane 8). For the aged sample studies, there would be the following additional four spots on the TLC plate: aged paper ink control (lane 9); aged paper ink irradiated (lane 10); aged paper control blank (lane 11); and aged paper irradiated blank (lane 12). It should also be noted that Adobe ${ }^{\circledR}$ Photoshop ${ }^{\circledR}$ was used to make minor corrections to the contrast and brightness of the ink bands shown on all of the TLC plates for better visualization.

A noticeable change in the ultraviolet fluorescence properties of the paper after irradiation was observed. Figure 5 shows the difference before and after irradiation for the unlined paper. Visibly, there was also a slight yellowing of those samples. It has been reported that a minimum radiation dosage as small as $2 \mathrm{kGy}$ can lead to unacceptable damage to cellulose-based paper

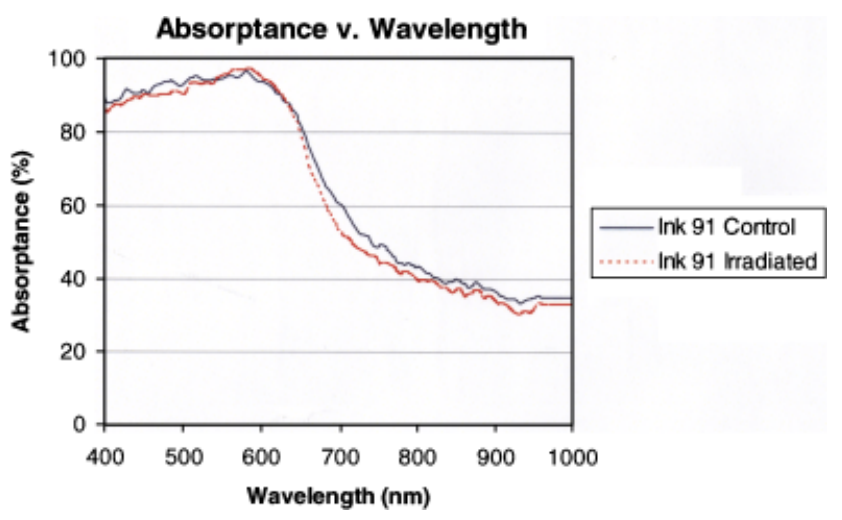

FIG. 6-A graph of the absorptance versus wavelength for ink 91 before and after irradiation. There are no significant differences between the absorptance values in these two graphs.

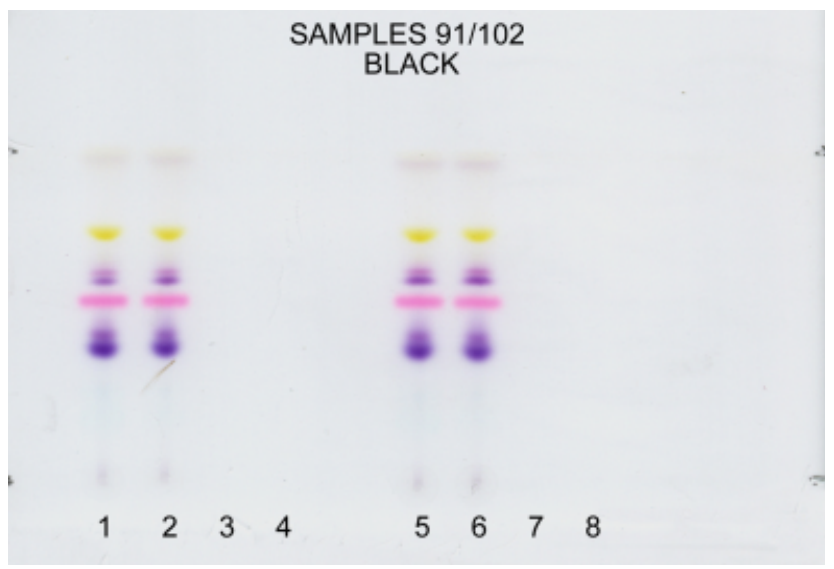

FIG. 7-An image of the TLC plate for ink samples 91 and 102. No detectable differences were observed between the control and irradiated ink samples.

(11). Dosages of $7 \mathrm{kGy}$ or higher were found to result in extensive oxidation and depolymerization. At higher dosages, additional reactions can occur including acidification, loss of strength, embrittlement, and discoloration of the paper.

\section{Black Inks}

As mentioned before, none of the black inks showed any detectable changes in any of the optical properties evaluated after irradiation. Figure 6 shows a graph of the absorptance spectra for the control and irradiated samples of one of the black inks (ink 91). Using solvent system 1 , neither the irradiated nor the control samples showed any additional or missing bands or altered mobilities when analyzed by TLC. Figure 7 shows an image of the chromatogram for ink 91.

\section{Blue, Red, Green, and Yellow Inks}

As with the black and blue inks, none of the blue red, green, or yellow irradiated samples showed any detectable changes in any of the optical properties. Nor were any additional or missing bands or altered mobilities detected when these samples were analyzed by TLC.

\section{Aged Samples}

Thirty-five inks that had been deposited on Whatman filter paper at varying times over the past 25 years were also analyzed using TLC. Using solvent system 1, neither the irradiated nor the control samples showed any additional or missing bands or altered mobilities when analyzed by TLC.

\section{Solvent System 2}

Approximately two dozen of the ink samples were re-analyzed using solvent system 2 . In some cases, the use of an alternate solvent system can improve band separation and resolution and assist in highlighting discrepancies. Solvent system 2 replaces ethyl acetate (solvent strength on silica gel of 4.4) with $n$-butanol (solvent strength on silica gel of 3.9). In addition, the solvent ratios in the system are different. In solvent system 1 , ethyl acetate comprises $52 \%$ of the system by volume, ethanol $26 \%$, and water $22 \%$. In solvent system $2, n$-butanol comprises $67 \%$ of the system by volume, ethanol $13 \%$, and water $20 \%$. None of the inks evaluated using solvent system 2 showed any unexplained differ- 
ences (e.g., discrepancies in band/spot intensities due to slight differences in spot concentrations on the TLC plate).

\section{Conclusions}

Unlike the author's previous experience with latent prints on paper (1), the irradiation process appears to have very little effect on the chemical analysis of writing inks. Of the 97 different inks evaluated in this study, none was found to have changed with respect to dye composition as a result of the irradiation process. These results appear to contradict earlier studies conducted on a more limited sample set $(3,4)$. It is difficult to compare directly the results from these previous studies as it is not possible to determine accurately the exact radiation dosages that the inks were exposed to during processing. In addition to internal variations in the radiation dosages possible during a single processing run, there have undoubtedly been changes (most likely decreases) in the overall radiation intensities implemented immediately after the anthrax letter attacks in October 2001. Initially after the attacks, there were considerably more reports of irradiationinduced damage to materials sent through the U.S. Postal Service $(12,13)$. There appear to be fewer of these reports now, which may support the theory of lower irradiation levels.

The overall results indicate that the paper type, solvent system, and the age of the ink samples did not have a significant effect on the TLC profiles for either the control or irradiated inks. Of the five ink colors tested, none appeared to be more susceptible to the irradiation process than any other. However, in one instance, the control sample from one ink was found to change color with time while the irradiated one remained stable. It is interesting to note that this phenomenon was observed only on lined paper and not with the unlined photocopy paper. The lined paper had a slightly acidic $\mathrm{pH}$ when tested, whereas the unlined photocopy paper had a slightly basic $\mathrm{pH}$. As most of the dyes used in the manufacture of ballpoint inks are basic dyes, it is possible that a chemical reaction may have occurred on the paper surface.

\section{Acknowledgments}

The authors would like to thank Ms. Janice Millhouse, United States Postal Service, for her assistance with irradiating the ink samples and Dr. Tony Cantu and Gerry LaPorte, United States Secret Service, and Doug Shaffer, Bureau of Immigration and Customs Enforcement, for their assistance in the editorial review of this manuscript.

\section{References}

1. Ramotowski R, Regen E. The effect of electron beam irradiation of forensic evidence. 1. Latent print recovery on porous and non-porous surfaces. J Forensic Sci 2005;50:298-306.

2. Tumosa CS, Erhardt D, von Endt D, El-Easely AM. Irradiation of mail: effects on archival museum materials. In: Komolprasert V, editor. ACS Symposium: effects of ionizing radiation on food and packaging. Washington, DC: American Chemical Society, 2004:314-23.

3. Tumosa CS, Erhardt D, Solazzo C. The effect on ballpoint pen and marker inks of chemical and electron beam remediation techniques for biological warfare agents. MAAFS Newsletter 2002;30(3):5-8.

4. Solazzo C, Tumosa CS, Erhardt D. The effect of electron beam irradiation on ballpoint pen and marker inks. MAAFS Newsletter 2004;32(2):13-6.

5. Hargett JW. The international ink library. Int Crim Pol Rev 1990;45:33-4.

6. Radiation information, http://www.epa.gov/radiation/terms/termghi.htm

7. Food irradiation, http://www.epa.gov/radiation/sources/food_irrad.htm

8. Becoming aware of radiation sources, http://www.epa.gov/radiation/ sources/mail_irrad.htm
9. Handbook of optics, volume 2: devices, measurements, and properties. 2nd edition. Bass M, editor. New York: McGraw-Hill Inc., 1995:25-4, 25-8.

10. The American Society for Testing and Materials (ASTM) Designation E1422-01. Standard guide for test methods for forensic writing ink comparison. West Conshohocken, PA: American Society for Testing and Materials, 2001:1-8 (CD-ROM version).

11. The effects on research specimens and museum collection items from electron beam irradiation of mail by the U.S. Postal Service, http:// www.si.edu/scmre/about/mail_irradiation.htm

12. Orzano M. Shipment of two silver certificates subjected to USPS mail irradiation.Coin World February 18, 2002:1, 90.

13. Orzano M. Silver coins tone during USPS irradiation. Coin World, March 4, 2002:1, 16.

APPENDIX A-A summary of black inks used in this study.

\begin{tabular}{|c|c|}
\hline Sanford Sharpie Ultra Fine Point & Felt-tip \\
\hline Sanford Vis-à-vis Wet Erase Fine Point & Felt \\
\hline Papermate Gelstick & Gel \\
\hline Papermate Widemate & Ballpoint \\
\hline Papermate Erasable Ink Medium Point & Ballpoint \\
\hline Papermate Erasable Ink Medium Point $(10 / 78) *$ & Ballpoint \\
\hline Papermate Rollerstick & Rollerball \\
\hline Papermate Flair & Felt-tip \\
\hline Gillette Papermate & Ballpoint \\
\hline Gillette Papermate (11/86) & Ballpoint \\
\hline Bic & Bulk Ink \\
\hline $\operatorname{Bic}(8 / 9 / 79)$ & Bulk Ink \\
\hline National & Bulk Ink \\
\hline National $(10 / 25 / 83)$ & Bulk Ink \\
\hline Pentel Energel $0.7 \mathrm{~mm}$ & Gel \\
\hline Pilot Dr. Grip & Gel \\
\hline Pilot Dr. Grip $(11 / 18 / 02)$ & Gel \\
\hline Hi-Point RTC Free Flow Rolling Pen & Gel \\
\hline Hi-Point RTC Free Flow Rolling Pen $(11 / 21 / 02)$ & Gel \\
\hline Pilot Erase-a-Gel & Gel \\
\hline Uniball Gellyz Scents UM 100 & Gel \\
\hline Papermate Gel Roller & Gel \\
\hline Papermate Gel Roller (11/18/02) & Gel \\
\hline Luxoz Ace & Ballpoint \\
\hline Luxoz Ace $(11 / 15 / 02)$ & Ballpoint \\
\hline Luxoz Sprint & Ballpoint \\
\hline National Ink Souvenir Pen WIMA 2000 & Ballpoint \\
\hline National Ink Souvenir Pen WIMA 2000 (6/26/02) & Ballpoint \\
\hline Hunt Elegant Writer Fine Permanent & Felt-tip \\
\hline Hunt Elegant Writer Fine Permanent (3/18/95) & Felt-tip \\
\hline Skillcraft Cushion Grip Medium & Ballpoint \\
\hline Papermate Tattoo Stick Medium & Gel \\
\hline Pilot Explorer Extra Fine & Rollerball \\
\hline Pilot Easytouch Medium & Ballpoint \\
\hline Papermate Medium Point & Ballpoint \\
\hline Skillcraft U.S. Government & Ballpoint \\
\hline Pentel Marker MS50 & Felt-tip \\
\hline Pentel Marker MS50 (3/78) & Felt-tip \\
\hline
\end{tabular}

*The date in parentheses denotes the actual date of that sample's deposition. The samples without such notations were prepared just before the beginning of this study. 
APPENDIX B-A summary of blue inks used in this study.

Bic Blue

BKA Souvenir Pen

Eppendorf Corporation Souvenir Pen

Sanford Uni-ball Fine

Netherlands Forensic Institute Souvenir Pen

University of Teeside Souvenir Pen

Pilot Supergrip Medium

Pilot Easytouch Fine

Bic Intensity Medium

Luxoz Ranger

Luxoz Ranger (11/15/02)*

Luxoz Ace grip

Pentel R100 Rolling Writer

Pentel Superball 02

Pentel MS50

Pentel MS50 (9/77)

Pentel SF50

Pilot Ball Liner

Pilot Superfine BP

Pilot Superfine BP (7/86)

Pilot Fineliner

Faber Castell Uniball

Faber Castell Wonderiter

Faber Castell Wonderiter (3/10/88)

Papermate Write Brothers Medium

Pilot Explorer Extra Fine

Skillcraft U.S. Governmant Fine

Hunt Elegant Writer Medium

Hunt Elegant Writer Medium (5/16/95)

Forensic Alliance Limited Souvenir Pen

Sakura Gelly Roll

Sakura Gelly Roll (6/12/02)

Pilot Precise Extra Fine

Sanford Sharpie Ultra Fine Point

Sanford Vis-à-vis Wet Erase Fine Point

Papermate Ultra Fine Flair

Papermate Rubberstick Medium Point

Papermate Rubberstick Medium Point (6/17/94)

Papermate Accu-point

Papermate Tattoo Stick Medium Point

Papermate Gel Stick

Papermate Widemate

Papermate Widemate $(7 / 15 / 02)$

*The date in parentheses denotes the actual date of that sample's deposition. The samples without such notations were prepared just before the beginning of this study.

APPENDIX C-A summary of red inks used in this study.

Pentel Flowing Writer SF50

Pentel B76

Pentel Sign Pen Chisel Tip

Pentel Sign Pen Chisel Tip (3/23/88)*

Pentel for Film PM2

Pilot Easytouch Medium

Pilot Razor Point II

Pilot Razor Point II (7/86)

Faber Castell Wonderiter

Faber Castell Superiter

Faber Castell Superiter (2/19/90)

Faber Castell Uniball Micro

Pentel Marker MS50

Sharpie Ultra Fine Permanent Marker

Pilot Explorer Extra Fine

Bic Intensity Medium

Crayola Red Marker

Crayola Red Marker (1/24/90)

Speedball Elegant Writer Medium Point

Sakura Gelly Roll Red

Sakura Gelly Roll Red (7/9/02)

Sanford Vis-à-vis Wet Erase Fine Point

Papermate Medium Point

Ballpoint

Ballpoint

Ballpoint

Rollerball

Ballpoint

Ballpoint

Ballpoint

Ballpoint

Gel

Ballpoint

Ballpoint

Ballpoint

Rollerball

Rollerball

Felt-tip

Felt-tip

Felt-tip

Rollerball

Ballpoint

Ballpoint

Plastic-tip

Rollerball

Plastic-tip

Plastic-tip

Ballpoint

Rollerball

Ballpoint

Felt-tip

Felt-tip

Ballpoint

Gel

Gel

Rollerball

Felt-tip

Felt-tip

Felt-tip

Ballpoint

Ballpoint

Rollerball

Gel

Gel

Ballpoint

Ballpoint

*The date in parentheses denotes the actual date of that sample's deposition. The samples without such notations were prepared just before the beginning of this study.

APPENDIX D-A summary of green inks used in this study.

Pentel for Film PM2

Pentel for Film PM2 (4/77)*

Sanford Vis-à-vis Wet Erase Fine Point

Pentel Rolling Writer

Pentel S510

Pilot Razor Point II

Pilot Razor Point II (7/86)

Pentech Metallicz

Pentech Metallicz (11/19/02)

Pentech Hot Sparklez

Sakura Gelly Roll Green

Sakura Gelly Roll Green (7/9/02)

Bic

Bic $(8 / 8 / 00)$

Scillcraft U.S. Government Medium Point

Bic Intensity Medium Point

Bic Intensity Medium Point (8/8/00)

Crayola Green

Felt-tip

Felt-tip

Felt-tip

Ballpoint

Felt-tip

Rollerball

Rollerball

Gel

Gel

Gel

Gel

Gel

Ballpoint

Ballpoint

Ballpoint

Gel

Gel

Felt-tip

*The date in parentheses denotes the actual date of that sample's deposition. The samples without such notations were prepared just before the beginning of this study.

APPENDIX E-A summary of yellow inks used in this study.

\begin{tabular}{ll}
\hline Fluorescents 54-32-A1 & Ballpoint \\
Pentel for Film PM2 & Felt-tip \\
Pentel for Film PM2 (4/77)* & Felt-tip \\
Crayola Yellow & Felt-tip \\
Crayola Yellow (8/89) & Felt-tip \\
Crayola Fluorescents & Felt-tip \\
Staedtler Textsurfer Classic & Felt-tip \\
Staedtler Textsurfer Classic (11/18/02) & Fet-tip \\
Gelly Roll Yellow & Gel \\
Crayola Pastels & Felt-tip \\
\hline
\end{tabular}

*The date in parentheses denotes the actual date of that sample's deposition. The samples without such notations were prepared just before the beginning of this study.

Additional information and reprint requests:

Robert S. Ramotowski, M.S.

Chemist

U.S. Secret Service

Forensic Services Division

950 H Street, NW

Washington, DC 20223
Felt-tip $\quad$ E-mail: robert.ramotowski@usss.dhs.gov
Ballpoint
Felt-tip
Felt-tip
Felt-tip
Ballpoint
Felt-tip
Felt-tip
Felt-tip
Felt-tip
Felt-tip
Ballpoint
Felt-tip
Felt-tip
Rollerball
Ballpoint
Felt-tip
Felt-tip
Felt-tip
Gel
Gel
Felt-tip
Ballpoint

Felt-tip

Ballpoint

Felt-tip

Felt-tip

Felt-tip

Felt-tip

Ballpoint

Felt-tip

Felt-tip

Gel

Felt-ti

\footnotetext{
然
}

